\title{
PODER LOCAL E EJA: SUAS RELAÇÕES COM AS POLÍTICAS PÚBLICAS EM SÃO JOÃO DE MERITI
}

\author{
Marcos Vinicius Reis Fernandes ${ }^{1}$ \\ Marcia Soares de Alvarenga ${ }^{2}$
}

\section{RESUMO}

Este artigo buscou analisar as relações entre poder local e EJA junto as políticas públicas no município de São João de Meriti/RJ. Percebeu-se a prática história de violação de direitos e de manutenção da relação estado-sociedade baseada no clientelismo, em que é negado o direito à cidade, onde se inscreve o direito à educação. No tocante à EJA verificou-se que a modalidade cumpre um papel potencial na garantia do direito constitucional à educação básica e que há uma relação orgânica e dialética entre o poder local hegemônico do território e a produção da desigualdade social através das políticas públicas elencadas.

Palavras-chave: Poder local. EJA. São João de Meriti.

\footnotetext{
${ }^{1}$ Mestre em Educação - Processos Formativos e Desigualdades Sociais pela UERJ. Membro do Grupo de Pesquisa e Extensão Políticas Públicas e Educação de Jovens e Adultos Trabalhadores (CNPq) e do Grupo de Estudos e Pesquisas Educação de Jovens e Adultos: contextos, sujeitos e práticas (CNPq). ORCID: https://orcid.org/0000-0001-6044-981X. Email: viniciusiserj@gmail.com.

2 Doutora em Educação pela UFRJ. Professora Associada da UERJ com atuação na graduação e no Programa de Pós-Graduação em Educação- Processos Formativos e Desigualdades Sociais. Procientista Faperj/UERJ. Coordenadora do Grupo de Pesquisa e Extensão Políticas Públicas e Educação de Jovens e Adultos Trabalhadores (CNPq) e do Grupo de Pesquisa Vozes da Educação (CNPq). ORCID: https://orcid.org/0000-00028686-9844. E-mail: msalvarenga@uol.com.br.
} 


\section{LOCAL POWER AND EJA: ITS RELATIONSHIPS WITH PUBLIC POLICIES IN SÃO JOÃO DE MERITI}

\section{ABSTRACT}

This article sought to analyze the relationship between local power and EJA along with public policies in the municipality of São João de Meriti/RJ. It was noticed the practical history of violation of rights and maintenance of the state-society relationship based on clientelism, in which the full right to the city, where the right to education is inscribed. With regard to EJA, it was found that the modality plays a potential role in guaranteeing the constitutional right to basic education and that there is an organic and dialectical relationship between the local hegemonic power of the territory and the production of social inequality through the listed public policies.

Keywords: Local power. EJA. São João de Meriti.

\section{EL PODER LOCAL Y EJA: SUS RELACIONES COM LAS POLÍTICAS PÚBLICAS EM SÃO JOÃO DE MERITI}

\section{RESUMEN}

Este artículo buscó analizar la relación entre el poder local y EJA junto con las políticas públicas en el municipio de São João de Meriti/RJ. Se notó la historia práctica de vulneración de derechos y mantenimiento de la relación Estado-sociedad basada en el clientelismo, en la que se niega el pleno derecho a la ciudad, donde se inscribe el derecho a la educación. Con respecto a EJA, se encontró que la modalidad juega un papel potencial en la garantía del derecho constitucional a la educación básica y que existe una relación orgánica y dialéctica entre el poder hegemónico local del territorio y la producción de desigualdad social a través de la ciudadanía catalogada. políticas.

Palabras clave: Poder local. EJA. São João de Meriti. 


\section{INTRODUÇÃO}

Em um país desigual como o Brasil, as periferias urbanas e rurais são caracterizadas pela negação de direitos e pela negligência na proposição e cumprimento de políticas públicas para a população trabalhadora. Neste contexto se insere o município de São João de Meriti, localizado na Baixada Fluminense, região metropolitana do estado do Rio de Janeiro.

São João de Meriti, assim como os demais municípios na condição de periferia do capitalismo dependente (FERNANDES, 2009), tem como marca histórica e social a prática do clientelismo, que é a estratégia política dos setores dominantes da sociedade. Por meio dessa prática, institui como favor, aos subalternizados uma série de direitos já constituídos nas legislações.

Entendemos que essa expressão do poder local reflete diretamente em um direito integral à cidade, onde os sujeitos são impedidos direta ou indiretamente de participar ativamente nas decisões a serem tomadas e das políticas a serem formuladas. Assim, através dessa relação clientelista muitas vezes só lhes são dadas a possibilidade marginal da participação. Nesse sentido, compreendemos como direito à cidade "[...] muito mais do que um direito de acesso individual ou grupal aos recursos que a cidade incorpora: é um direito de mudar e reinventar a cidade mais de acordo com nossos mais profundos desejos" (HARVEY, 2014, p. 28).

No contexto educacional, os dados do Censo 2010 do IBGE apontam que, no município de São João de Meriti, a proporção de jovens na faixa etária de 18-20 anos com o Ensino Médio completo era de $40,87 \%$, e no universo da população a partir dos 25 anos de idade apenas $31,2 \%$ havia concluído essa etapa da educação básica. Logo, a expectativa de anos de estudo da população do município era de 9,2 anos (IBGE, 2011).

A despeito de a educação ser declarada "[...] direito de todos e dever do estado e da família" (BRASIL, 1988), pode-se considerar que existe uma distância entre o declarado e o realizado, já que grandes contingentes populacionais da sociedade brasileira não têm acesso ou têm esse direito fragmentado. Devido a essa contradição, que é inerente da sociedade capitalista, ainda hoje, no século XXI, o 
Brasil não conseguiu universalizar o acesso e nem garantir a permanência dos filhos e filhas da classe trabalhadora a todo percurso da educação básica.

Expressão dessa incompatibilidade, tem-se como modalidade da educação básica a Educação de Jovens e Adultos (EJA), sendo destinada "àqueles que não tiveram acesso ou continuidade de estudos no ensino fundamental e médio na idade própria e constituirá instrumento para a educação e a aprendizagem ao longo da vida" (BRASIL, 1996).

Nesse sentido, buscamos trazer elementos que nos auxiliem a problematizar e compreender a negação de direitos nas políticas públicas deste município, em consonância com o poder local e a modalidade EJA. Como aporte teórico-metodológico fizemos uso de dados abertos de instituições especializadas e de autores e autoras que estudam e pesquisam a modalidade a partir de uma perspectiva crítica, tal como alguns estudos sobre a região da Baixada Fluminense, em especial São João de Meriti.

Sendo assim, o estudo foi dividido em três seções, além desta introdução e da conclusão. Na primeira, intitulada de movimentos de luta e resistência na baixada, busca-se contextualizar duas ações voltadas para o campo educacional, uma institucionalizada pelo poder público e outra inserida no contexto dos movimentos sociais, a saber: o Projeto Baixada e o pré-vestibular social EDUCAFRO. A segunda realiza uma discussão sobre o Poder local no território de São João de Meriti. Na terceira e última seção analisa-se o contexto da EJA no município.

\section{MOVIMENTOS DE LUTA E RESISTÊNCIA NA BAIXADA}

A região da Baixada Fluminense é popularmente conhecida pela negação de direitos à sua população e pela violência sistêmica noticiada constantemente pelos canais de jornalismo. Contudo, nesse mesmo espaço, há tensionamentos de luta e resistência que buscam a construção de um território mais democrático e inclusivo. É a partir desse pressuposto que se inserem as ações que iremos abarcar nesta seção. 
Como desdobramento da transição entre o findar do período da ditadura empresarial-militar (1985) e o iniciar da redemocratização (1985) há uma maior inserção de profissionais progressistas junto aos projetos de educação implementados no país. No que se refere à educação voltada aos jovens e adultos, encerrava-se, em 1985, o ciclo da política federal Movimento Brasileiro de Alfabetização (MOBRAL), uma instituição que independente do Ministério da Educação exercia suas ações por meio de programas, entre eles os Programas de Alfabetização Funcional e o de Educação Integrada, voltados para alfabetização e pós-alfabetização, respectivamente. Com isso, junto ao MEC, criou-se um órgão de fomento denominado Fundação Nacional para Educação de Jovens e Adultos, conhecido pela sigla Educar.

O MOBRAL tinha como objetivo "erradicar o analfabetismo", utilizando-se de uma imposição ideológica voltada para manutenção da hegemonia do governo ditatorial. Contudo, segundo Andrade (1993), o projeto concebeu-se fracassado com o resultado da eleição legislativa de 1974, ademais pesquisadores mostraram que apenas $15 \%$ de seus estudantes conseguiam chegar ao final do curso. Já a Fundação Educar surgia em um período que

[...] por mais clara que pudesse estar a composição
ainda autoritária do chamado governo da 'Nova
República', ocorriam sensíveis modificações, que
traziam esperanças, principalmente pelo alívio
causado pelo fim do regime militar e pela
constatação de que vários cargos da administração
pública vinham sendo ocupados por profissionais
considerados comprometidos com a
'democratização da educação' (ANDRADE, 1993, p.
4).

No contexto dessa mudança, institui-se dentro da Fundação Educar um grupo de dez educadores, com formações distintas, que pensam e formulam um projeto de atendimento a jovens e adultos analfabetos junto aos municípios de Duque de Caxias, Nova Iguaçu e São João de Meriti, da periferia urbana do estado do Rio de Janeiro localizada na Baixada Fluminense. Esses educadores pautavam-se em pressupostos de uma educação crítica voltada para a transformação 
social e tinham como ideal à práxis pedagógica de Paulo Freire. Desse modo, entendiam a educação

[...] enquanto processo de compreensão crítica da realidade, tinha que estar necessariamente articulada ao projeto político de transformação social, mediante o estabelecimento de práticas educacionais democráticas que envolvesse a descentralização das decisões e participação efetiva dos grupos organizados da sociedade civil (ANDRADE, 1993, p. 9).

Em parceria com movimentos sociais, associação de moradores e com a Igreja Católica iniciou a materialização do Projeto. Ressalte-se o papel central que a Igreja Católica exerceu a partir da inauguração da diocese da Baixa, instalada em 1981 na cidade de Duque de Caxias, tendo como posicionamento político social a Teologia da Libertação, perspectiva crítica progressista da instituição.

Como característica marcante dos sujeitos da EJA, os estudantes do Projeto tinham a marca da classe trabalhadora, sujeitos expropriados pelas relações de produção do sistema capitalista. A grande maioria com salários ínfimos, onde 54\% ganhavam menos que um salário-mínimo e 41,4\% recebiam entre um e dois salários. No tocante a idade já se expressava o que hoje entende-se como juvenilização da EJA, tendo o percentual de 63,9\% na faixa-etária de 15 a 25 anos (MONTEIRO, 2007).

A política da Fundação Educar contribuiu para inclusão cidadã e participação política de indivíduos que se encontravam à margem das ações do Estado e que eram compreendidos no bojo da ditadura militar através de uma pedagogia que se voltava apenas à leitura e escrita, direcionada especialmente para uma perpetuação do projeto político em vigor através de eleições futuras.

Desse modo, no novo contexto político e a partir da implementação do Projeto Educar para Baixada

[...] apresentava, entre seus objetivos, o incentivo aos debates sobre cidadania e à participação no movimento social, esses jovens puderam construir suas identidades com uma reflexão ancorada na 
relevância do envolvimento em movimentos organizados da sociedade. Os jovens participantes do projeto, através da frequência às aulas que ocorriam em sedes de associações ou em igrejas, começavam, desse modo, a ocupar o espaço público do seu bairro, tendência que, aos poucos, poderia ser ampliada, abrindo-se para outros espaços da cena pública (MONTEIRO, 2007, p. 28).

Essa iniciativa vinculada à educação de jovens e adultos foi premiada em 1988 pela Unesco como a melhor experiência na área da EJA, com participação popular, dentre mais de 150 ações de diversos países (ANDRADE, 1993). Contudo, em 1990, com a assunção de Fernando Collor de Mello à presidência da República, o Projeto foi interrompido de forma arbitrária e sem um mínimo diálogo.

Nesse mesmo contexto, na década de 1990, surge mais uma ação de resistência com participação da sociedade civil voltada para transformação e inclusão da população. A Educação e Cidadania de Afrodescendentes e Carentes (EDUCAFRO) nasce como espaço de pré-vestibular social fundando pelo Frei David Raimundo dos Santos e fruto da parceria entre franciscanos e militantes do movimento negro local. Cabe ressaltarmos que parte dos componentes da EDUCAFRO eram oriundos de um outro curso social do território denominado Pré-vestibular para Negros e Carentes (PVNC), demonstrando assim um percurso de luta e resistência já instituído no local.

O primeiro núcleo da EDUCAFRO nasceu na igreja matriz franciscana no bairro de São Mateus em São João de Meriti. Toda a ação fora baseada na ação comunitária local e tinha como objetivo a inserção da população negra e carente nas universidades públicas e privadas, o que vai se consolidar com advento de bolsas, uma luta que tais movimentos ajudaram a construir.

A EDUCAFRO atuou nas lutas pela implementação das políticas de ações afirmativas na UERJ, primeira universidade brasileira a implementar cotas raciais, e nas universidades públicas em nível nacional. Essa atuação em favor das cotas continua atualmente. Em 2018, no contexto da reavaliação da política de ação afirmativa da UERJ pela Assembleia Legislativa 
do Rio de Janeiro (ALERJ) a EDUCAFRO esteve presente, e, essa reavaliação foi pauta de reuniões gerais, onde os estudantes eram conclamados à luta pela manutenção do sistema de cotas raciais na Universidade (SANTOS, 2019, p. 34).

A experiência da EDUCAFRO em São João de Meriti potencializou a criação de cursos com o objetivo de promoção social através da inclusão de jovens e adultos trabalhadores nas universidades. Hoje existem centenas de pré-vestibulares social espalhados por todos os cantos do país e a EDUCAFRO está presente na Baixada Santista-SP, Brasília-DF, Rio de Janeiro-RJ, Belo HorizonteMG e Bragantina-PR.

Desse modo, podemos compreender que o município de São João de Meriti, assim como a região da Baixada Fluminense, possui em sua historicidade a atuação de movimentos sociais e da sociedade civil que buscam a transformação social através da educação.

\section{SÃO JOÃO DE MERITI E PODER LOCAL}

Buscando superar a prática enraizada do clientelismo, uma vez que os municípios eram vistos como espaços propícios para tal, com o advento da Constituição Federal (CF) de 1988 ganharam maior protagonismo político, sendo elevados à classificação de entes federativos. Na ocasião, buscou-se a descentralização das decisões e por consequência maior autonomia do poder local, refletindo, deste modo, na municipalização de serviços públicos que visam garantir o atendimento de direitos fundamentais/elementares de sua população, tais como: saúde, transporte público, educação infantil e ensino fundamental e saneamento básico (SANTIN; FAVRETTO, 2017).

Na observação de Alvarenga (2008), a CF/1988 consolidou o movimento de criação de municípios que vinha acontecendo desde o ano de 1940. Contudo, a autora relata que, contraditoriamente, mesmo com essa nova classificação como entes federados autônomos, muitos dos municípios não conseguem garantir sua autonomia como poder governamental. Essa questão se dá fruto da falta de recursos econômicos próprios para que sejam capazes de 
implementar políticas públicas. Tal realidade expõe a dicotomia centralização $x$ descentralização.

Quanto à descentralização, que é o modelo abarcado a partir da legislação em vigor, há que se pensar dois modelos distintos, ou seja, que podem se desenvolver através de uma concepção democrática: representativa ou participativa. A primeira, é baseada ideologicamente em uma aproximação resultante de um processo de descentralização. Contudo, apesar da proximidade, restringe-se à população, essencialmente, a execução das decisões tomadas pelo poder central que a representa. Já na democracia participativa, os segmentos locais participam da concepção e da formulação das políticas a serem implantadas.

A descentralização, nessa perspectiva, além do fortalecimento do poder local exige, concomitantemente, o estabelecimento de outras relações entre o Estado e a sociedade, de modo que os canais de participação e decisão por parte da população se alarguem, proporcionando uma maior fluidez das suas demandas, efetivando uma maior participação dos setores locais na gestão dos serviços públicos (ALVARENGA, 2008, p. 122-123).

Nesse sentido, o modelo político democrático descentralizado participativo busca uma inserção propositiva dos movimentos sociais organizados, conselhos municipais, sociedade civil, entre outros na formulação de políticas para a sociedade local.

Ao analisarmos sobre poder local, também, devemos considerar as relações de poder que se estabelecem entre os diferentes atores sociais, bem como entre as diferentes esferas governamentais que ultrapassam para além da municipal. Desse modo, o local não é apenas fisicamente localizado, mas socialmente construído (FISCHER, 1993).

Destarte, para analisarmos a realidade de São João de Meriti é imperativo compreender a inserção do território da Baixada Fluminense como periferia metropolitana situada às margens do município do Rio de Janeiro. Região que de início se dava majoritariamente como um conglomerado de sub-regiões do município Nova Iguaçu e posteriormente foi se dividindo em demais 
municípios. Esse território é estigmatizado como espaço atrasado social e economicamente e de alto índice de violência. Rocha (2020) nos ajuda a compreender o papel da representação social sobre a Baixada Fluminense no processo de construção e produção do espaço, sua materialidade, ao formular que

A construção das realidades geográficas é dotada de materialidade, como forma concreta, mas também é forjada por ideações, imagens e simbologias que constituem uma dimensão imaterial, oriunda das relações entre os sujeitos e o(s) espaço(s). Neste sentido, as múltiplas categorias que fazem parte de nossas experiências de vida, são dotadas de espacialidade que contém materialidade e representação (ROCHA, 2020, p. 13).

No que se refere à temática trabalho e remuneração, o município possui uma situação bem preocupante, pois segundo dados do IBGE:

Em 2018, o salário médio mensal era de 1.9 saláriosmínimos. A proporção de pessoas ocupadas em relação à população total era de $12.9 \%$. Na comparação com os outros municípios do estado, ocupava as posições 54 de 92 e 72 de 92, respectivamente. Já na comparação com cidades do país todo, ficava na posição 2678 de 5570 e 2651 de 5570, respectivamente. Considerando domicílios com rendimentos mensais de até meio saláriomínimo por pessoa, tinha $35.4 \%$ da população nessas condições, o que o colocava na posição 38 de 92 dentre as cidades do estado e na posição 3484 de 5570 dentre as cidades do Brasil (IBGE, 2020).

É alarmante a cidade com maior montante de pessoas por metro quadrado do país ter apenas $12,9 \%$ de sua população ocupada. Esse dado insere São João de Meriti como um dos vinte piores municípios do estado no que se refere à proporção de pessoas ocupadas. 
Com relação ao desenvolvimento econômico, tem-se como característica principal o setor de serviços, através do Shopping Grande Rio e do comércio localizado próximo à malha ferroviária e nas margens da Rodovia presidente Dutra, além da oferta de força de trabalho de seus residentes aos municípios vizinhos, em especial à capital do estado, devido a demanda de vagas de trabalho ser menor que a oferta de mão de obra. Face a isto, o município de São João de Meriti vem construindo, ao longo dos anos, uma dependência junto à cidade do Rio de Janeiro no tocante à ocupação de postos de trabalho para/por seus habitantes.

Como agente produtor do espaço urbano, o Estado, 'organizou' territorialmente São João de Meriti sem grandes espaços para a expansão industrial, e a grande tendência de áreas ocupadas para moradias no contexto metropolitano na década de 1950 e 1960, se consolidou a imagem de cidade com característica de dormitório. (LAPORT, 2013, p. 31).

Na questão da saúde pública a situação também não é diferente. Destaque-se que entre os 92 municípios do estado, segundo dados abertos do Ministério da Saúde expostos no portal eletrônico do IBGE Cidades referentes ao ano de 2017, São João de Meriti ocupou a posição 18 , no correspondente à taxa de mortalidade infantil $^{3}$; e a quinta posição em número de óbitos ${ }^{4}$ referentes a crianças com idade inferior a 1 ano (BRASIL, 2017).

Quanto ao saneamento básico, segundo dados apurados pela organização "Trata Brasil", no ano de 2017 três municípios da Baixada Fluminense amargavam realidades assustadoras quanto ao índice de esgoto tratado referente à água consumida: Duque de Caxias (3,89\%), Nova Iguaçu (0\%) e São João de Meriti (0\%).

Seis municípios apresentaram valor máximo (100\%) de tratamento de esgoto, e 16 municípios valores superiores a $80 \%$ sendo considerados universalizados no contexto deste Ranking. O mínimo que os municípios possuem de tratamento

${ }^{3}$ Óbitos por mil nascidos vivos.

${ }^{4}$ Óbitos em números absolutos. 
de esgoto é $0 \%$, que é o caso de três municípios (Governador Valadares-MG, Nova Iguaçu -RJ e São João de Meriti-RJ; Ananindeua -PA possuí índice de tratamento de 0,91\%) (INSTITUTO TRATA BRASIL, 2018, p. 59).

Essa difícil realidade econômica e social do povo meritiense reflete as causas e consequências de um projeto instituído e instituinte de poder local que se apregoa em todo território da Baixada Fluminense.

Pensamos que a elaboração hegemônica da representação do território da Baixada Fluminense já se dá inicialmente através das conotações que a nomeiam. São muitas, dentre as quais temos: "área de residência de pessoas baixas", "área de matador", "território de desova" entre outras. Este território sempre foi marcado e reconhecido, sobretudo, no período 1970-1990, com apoio da mídia existente, como um espaço estigmatizado por extermínios recorrentes, comandados por pessoas e/ou grupos que se relacionavam com instituições do Estado, seja nos poderes executivos e/ou legislativos locais (ROCHA, 2020).

Essa relação que permeou o mundo das representações também acontece no mundo concreto, refletindo ainda hoje numa realidade que, na última década e meia, vem sendo marcada por casos de execuções em massa, popularmente conhecidos como chacinas, tendo como alvo de extermínio sobretudo a juventude negra. Em março de 2005, registrou-se na região a maior chacina do estado do RJ, em que 29 pessoas foram assassinadas por policiais fora do horário de serviço, que transitaram entre os municípios de Nova Iguaçu e Queimados atirando a esmo nas pessoas. Segundo investigações decorrentes do depoimento de uma testemunha, um policial militar, que fora executado logo após esse depoimento, o que motivou esse crime bárbaro foi a insatisfação de parte dos policiais com a "linha dura" imposta nos batalhões da PM contra casos de corrupção. ${ }^{5}$

Em julho de 2019, desta vez em Belford Roxo, fora registrada 4 mortes e 11 pessoas feridas. O cenário se deu de modo similar ao

\footnotetext{
${ }^{5}$ Disponível em: https://bityli.com/xnsd7.
} 
anterior. Homens encapuzados desceram de um carro e atiraram contra pessoas que estavam confraternizando em um bar. Segundo as reportagens, o motivo seria a busca de um miliciano por traficantes, motivados pela busca do domínio territorial local. ${ }^{6}$

O mais recente dos episódios aconteceu no dia 12 de dezembro de 2020. Dois jovens transitavam de moto em Belford Roxo, quando foram brutalmente abordados por dois policiais militares. Nesta abordagem, um policial atira em direção aos jovens, que após o ocorrido são imobilizados e colocados na viatura. Depois disso, os jovens foram encontrados mortos com sinais de tortura. Esses jovens não apresentavam risco algum aos policiais e a qualquer outra pessoa. O caso só foi descoberto devido a uma câmera de segurança existente no local. Os policiais foram presos. ${ }^{7}$

Casos similares ao exposto acima têm sido cada vez mais recorrentes em áreas periféricas, onde seus moradores têm cor, classe social e endereços definidos, ou seja, jovens pretos, favelados e periféricos.

Pode-se dizer que os grupos paramilitares, popularmente conhecidos como milícias, obtiveram uma base organizacional e operacional importante junto aos grupos de extermínio, oriundos da época da ditadura militar, localizados na Baixada Fluminense. Segundo Goulart e Florentino (2020, p. 2), foi a partir desse período histórico

que esses grupos iniciaram o alicerce de uma estrutura de poder que nunca sofreu qualquer tipo de impedimento, pelo contrário, que se fortalece até os dias atuais, sendo os embriões da estrutura de poder das atuais milícias. Neste mesmo período histórico, as principais famílias e grupos de matadores e exterminadores consolidaram o poderio político e letal nos diversos territórios da Baixada, sendo o embrião da atual face da violência urbana fluminense. Estamos em um cenário de consolidação da milícia como um projeto político

\footnotetext{
${ }^{6}$ Disponível em: https://bityli.com/rsaSS.
}

${ }^{7}$ Disponível em: https://bityli.com/aAqV. 
do Estado para áreas suburbanas, faveladas e periféricas.

Essa relação tem implicância direta nas eleições e vem refletindo em casos cada vez mais frequentes de execuções de précandidatos, candidatos e de pessoas que trabalham como cabo eleitoral. De 2019 até agosto de 2020, foram registradas 10 vítimas.

Há denúncias e investigações de que nos territórios dominados pelos grupos paramilitares somente candidatos associados a eles podem fazer campanha e que os moradores são coagidos a votar nos mesmos. O controle do voto é realizado da seguinte forma: através de ações assistencialistas, por meio das quais tentam passar uma imagem de benfeitores (convencimento), ou ameaçando os moradores, até mesmo dizendo que irão conferir os votos em cada seção eleitoral da região (força). Gramsci (2005) nos ajuda a interpelar essa realidade para compreensão do Estado junto à superestrutura, através de categorias que compõem a dialética entre sociedade política e sociedade civil; Coerção e hegemonia.

Conforme discorremos anteriormente e embasados em dados do próprio Atlas da Violência.

No Brasil, os homicídios são a principal causa de mortalidade de jovens, grupo etário de pessoas entre 15 a 29 anos. Esse fato mostra o lado mais perverso do fenômeno da mortalidade violenta no país, na medida em que mais da metade das vítimas são indivíduos com plena capacidade produtiva, em período de formação educacional, na perspectiva de iniciar uma trajetória profissional e de construir uma rede familiar própria (IPEA, 2020 p. 20).

São esses jovens que são os potenciais educandos da Educação de Jovens e Adultos. Foi pensando nisso que voltamos a nossa análise para a juventude da Baixada Fluminense, em especial, de São João de Meriti, com vista na interpretação e superação do que está no aparente dos dados atinentes ao quantitativo de: matrículas escolares, escolas e migração para EJA. 


\section{A EJA NO CONTEXTO DE SÃO JOÃO DE MERITI}

Somando todas as escolas, privadas e públicas, instaladas no município, São João de Meriti possuía, em 2019, 2.245 estudantes matriculados em turmas de Educação de Jovens e Adultos de Ensino Médio (EJA/EM). Essas incluíam matrículas da modalidade presencial, semipresencial, Curso FIC integrado à EJA/EM e Curso Técnico (EM) integrado à EJA. Desse total, a maior parte (92,3\%), 2.073, correspondia as matrículas sob dependência administrativa EDUC. Dessas matrículas vinculadas à rede estadual temos que $73 \%$ (1.528) são estudantes na faixa etária 18-29 anos e 63\% (1.320) estão com idades entre 18-24 anos (INEP, 2020).

Analisando os dados da EJA do Ensino fundamental no município estudado, podemos verificar um percentual considerável de estudantes na faixa etária de 15 a 17 anos matriculados na modalidade. Das 230 matrículas geridas pela SEEDUC, 45,6\% (105) são de adolescentes, já na rede municipal esse percentual é de 30,56\% (625) dentre as 2.045 matrículas (INEP, 2020).

Entendemos que a rede estadual apresenta um percentual maior devido oferecer apenas os anos finais desta etapa da educação. Como os dados da Secretaria Municipal trazem o somatório das matrículas atinentes aos anos iniciais e finais há uma queda no índice, visto que na EJA há uma tendência em se ter um percentual maior de matrículas de pessoas adultas e idosas nos anos iniciais do ensino fundamental.

A partir dessa realidade, entendemos que a juvenilização da EJA, compreendida como jovens que poderiam estar cursando esta etapa de ensino sem frequentar a modalidade EJA, demanda ser estudada como um fenômeno histórico e socialmente produzido, pois compreende sujeitos que pelas suas condições de vida e trabalho migraram ou foram induzidos pelas políticas de Estado à matrícula nesta modalidade.

Indo ao encontro desse número expressivo de jovens matriculados na modalidade em São João de Meriti, tem-se que no período de 2007 a 2019 a rede municipal reduziu em aproximadamente $30 \%$ o número de matrículas no ensino 
fundamental regular e que a rede estadual reduziu em 16,7\% o número de matrículas no ensino médio regular.

Essa redução de matrícula na escola regular tem como fator preponderante as ações demandadas por organismos internacionais, tais como Banco Mundial, OCDE, Unesco, entre outros, que impactam nas políticas públicas implementadas pelas secretarias de educação. Sob as orientações destes organismos, as secretarias de educação têm dinamizado estratégias para reduzir as taxas de distorção sérieidade com a finalidade de regularizar o índice de fluxo escolar.

A exclusão desses sujeitos da escola regular no município de São João de Meriti, segundo estudo do Tribunal de Contas do Estado do Rio de Janeiro (TCE-RJ), mostra que "mesmo que haja uma tendência de redução de distorção série-idade, se ocorre queda desse indicador entre uma série e a seguinte no decorrer dos anos, isso representa evasão escolar" (TCE-RJ, 2019, p. 46). Esse mesmo estudo evidencia que houve uma variação negativa de $38 \%$ do total de estudantes que concluíram o ensino fundamental se comparados os anos de 1998 e 2018.

Entendemos que a questão social implica diretamente nas trajetórias dos educandos no processo de escolarização. Por isso, buscamos interpelar as condições materiais de vida da população para superar com o aparente do real. Segundo a Confederação Nacional dos Municípios ${ }^{8}, 13,94 \%$ da população de São João de Meriti vivia em extrema pobreza no ano de 2019. Chamamos a atenção para a brusca elevação desse percentual que vinha se mantendo estável nos últimos anos em 9\%. Pessoas em extrema pobreza, de acordo com parâmetro nacional, são aquelas com renda mensal menor que $\mathrm{R} \$ 85,00$.

A elevação desse percentual é fruto da degradação das políticas sociais, sobretudo federais, que garantem a essa população condições mínimas de dignidade e vida. Essas famílias, quase 14\% da população de São João de Meriti, são as mais exploradas visto as suas condições sociais e econômicas para a (re)produção da vida. Seus filhos e filhas buscam trabalho, em geral informal, para contribuírem

\footnotetext{
${ }^{8}$ Disponível em: https://bityli.com/LRD6M.
} 
na aquisição e consumo de gêneros alimentícios e nas despesas domésticas em geral. Nesta dinâmica, na luta pela sobrevivência, as expectativas de completar a escolarização básica são reduzidas e adiadas, diante da emergência em verem atendidas as necessidades radicais nos limites da existência. Em $A$ ideologia alemã, Marx e Engels já nos revelava sobre essas necessidades básicas humanas ao formularem que é fundamental para o histórico desenvolvimento dos homens a produção concreta da vida através do trabalho que leva a suprir as necessidades primárias materiais de vida, tais como vestirse, alimentar-se, beber, ter moradia etc. (MARX; ENGELS, 1987).

Nessas condições, é fundamental a implementação de políticas públicas que garantam a permanência dessas crianças, adolescentes e jovens na escola, que vá para além da garantia formal expressa na Constituição Federal de 1988, na Lei de Diretrizes e Bases da Educação Nacional e no Estatuto da Criança e do Adolescente.

Isto posto, entendemos conceitualmente a categoria juventude que abarca esses sujeitos, construída social e historicamente a partir da posição que ocupa na sociedade, leva jovens, sobretudo das periferias urbanas, a experenciarem os mesmos acontecimentos e problemas similares de acordo com a pertença de classe, gênero, raça, trabalho e moradia. Sendo assim, não pode ser reduzida a uma mera compreensão de recorte etário comum.

Com relação a classe social, ao considerarmos que a modalidade possui um recorte demarcado como classe trabalhadora, entendemos que a classe se dá quando homens e mulheres, a partir de experiências comuns, herdadas ou divididas, vivenciam e mobilizam seus interesses comuns. E, também, enquanto força social, de se organizar e consolidar posições nas lutas por seus direitos e nas disputas por hegemonia, podendo, assim, haver "luta de classes sem classe", pois as formas de classe, nessa sociedade, ainda não são conscientes

a experiência de classe é determinada, em grande medida, pelas relações de produção em que os homens nasceram, ou entraram involuntariamente. A consciência de classe é a forma como essas experiências são tratadas em 
termos culturais. (THOMPSON, 1987, p.10, grifo nosso)

No debate, entendendo a educação como parte estruturante da sociedade de classes no sistema capitalista, há que se considerar que

Além da reprodução, numa escala ampliada, das múltiplas habilidades sem as quais a atividade produtiva não poderia ser realizada, o complexo sistema educacional da sociedade é também responsável pela produção e reprodução da estrutura de valores dentro da qual os indivíduos definem seus próprios objetivos e fins específicos. As relações sociais de produção capitalistas não se perpetuam automaticamente (MÉSZÁROS, $1981 \mathrm{p}$. 260).

Nessa perspectiva de uma sociedade constituída a partir de classes, a EJA representa, do ponto de vista de sua inserção no sistema educacional da sociedade capitalista, uma modalidade de produção e reprodução dos que não tiveram acesso ou não concluíram sua escolarização em idade socialmente considerada como a ideal e o fenômeno da juvenilização espelha uma aceleração desse processo.

De acordo com a realidade concreta de São João de Meriti, entendemos que há uma grande barreira para que o município possa cumprir o estipulado pelo Plano Nacional de Educação (PNE). Desse modo, a modalidade EJA que deveria ser extinta ao longo do tempo, ao menos nos pressupostos que funciona hoje, como uma modalidade de educação básica que atende jovens logo completem a idade mínima para matrícula, tem um papel fundamental na garantia do direito à educação básica da classe trabalhadora.

\section{CONSIDERAÇÕES FINAIS}

Face ao exposto, buscamos trazer a materialidade vivenciada pela população de São João de Meriti na busca de compreender a relação Poder Local e Educação de Jovens e Adultos, perante o 
contexto das políticas públicas, de modo a superar o que vem sendo naturalizado neste território periférico do estado do Rio de Janeiro.

Através dos dados abarcados podemos entender que há um processo histórico em curso, de manutenção na perpetuação da subordinação da população trabalhadora para um processo relacional que vem se mantendo, mesmo que através de atualizações, de clientelismo.

Não podemos desassociar as ações tomadas pelo Estado das demandas impostas pelos organismos internacionais, tanto no âmbito das políticas educacionais, com implementação de currículos e (des)autonomia pedagógica, quanto as políticas sociais que vêm desmantelando direitos historicamente conquistados pela classe trabalhadora, pois "em síntese, as economias dependentes foram transformadas em mercadoria, negociáveis a distância, sob condições seguras e ultra-lucrativas" (FERNANDES, 2009, p. 17).

Nesse sentido, entendemos que há uma relação orgânica e dialética entre o poder local hegemônico do território e a produção da desigualdade social através das políticas públicas elencadas que excluem da participação setores populares da sociedade e que acabam refletindo na produção da negação do direito à cidade, tal como à educação da juventude meritiense.

Concluímos esse texto defendendo que a EJA, enquanto direito público subjetivo, cumpre um papel fundamental na garantia da escolarização de parcela significativa da população de São João de Meriti que, durante os ciclos de vida da infância e da adolescência, teve negado o direito ao acesso, à permanência e à aprendizagem dos conhecimentos socialmente produzidos. Nesse sentido, dialogamos a favor de uma educação onde os jovens, adultos e idosos trabalhadores sejam sujeitos ativos do/no processo de ensinoaprendizagem. Busca-se, também, a desnaturalização dos fenômenos sociais para sua apreensão crítica, ou seja, uma EJA que eleve o pensamento à síntese das múltiplas determinações que a conformam como modalidade de ensino social e historicamente produzida em vista aos seus limites e potencialidades à escolarização e emancipação de jovens e adultos trabalhadores. 


\section{REFERÊNCIAS}

ALVARENGA, M. S. Movimentos sociais e poder local: limites e possibilidades dos conselhos participativos nas lutas pelo direito à educação. Perspectivas em Políticas Públicas, Belo Horizonte: UEMG, v. 1, n. 1, p. 115-131, jan./jun. 2008.

ANDRADE, E. R. Nos limites do possível: uma experiência políticopedagógica na Baixada Fluminense. 1993. 106f. Dissertação (Mestrado em Educação) - Instituto de Estudos Avançados em Educação, FGV, Rio de Janeiro, 1993.

BRASIL. Constituição (1988). República Federativa do Brasil. Brasília, DF: Senado Federal, 1988. Disponível em: https://bityli.com/bTtAt. Acesso em 21 abr. 2021.

BRASIL. Lei $\mathbf{n}^{\circ}$. 9.394, de 20 de dezembro de 1996. Lei de Diretrizes e Bases da Educação Nacional. Disponível em: https://bityli.com/91Wfj. Acesso em 21 abr. 2021.

BRASIL. Ministério da Saúde. Secretaria de Vigilância em Saúde. Sistema nacional de vigilância em Saúde: Rio de Janeiro. Brasília, DF: Ministério da Saúde, 2007.

FERNANDES, F. Capitalismo dependente e classes sociais na América Latina. 4 ed. São Paulo: Editora Globo, 2009.

FISCHER, T. Poder Local, Governo e Cidadania. Salvador: Fundação Getúlio Vargas, 1993.

GOULART, F.; FLORENTINO, G. Milícias e as eleições de 2020 na

Baixada Fluminense. Rio de Janeiro: Brasil de Fato. 2020. Disponível em: https://bityli.com/T5izk. Acesso em: 14 dez. 2020.

GRAMSCI, A. Cartas do cárcere. Trad. de Luiz S. Henriques. Rio de Janeiro: Civilização Brasileira, 2005.

HARVEY, D. Cidades rebeldes: do direto à cidade à revolução urbana. São Paulo: Martins Fontes, 2014.

IBGE. Censo Demográfico 2010. Rio de Janeiro: 2011. Disponível em https://bityli.com/oLkC2. Acesso em 21 abr. 2021. 
IBGE. Pessoal Ocupado. Rio de Janeiro: IBGE, 2020. Disponível em: https://bityli.com/Hbgxc. Acesso em 10 out. 2020.

INEP. Sinopse Estatística da Educação Básica 2019. Brasília: 2020. Disponível em: https://bityli.com/ELnUO. Acesso em: 26 ago. 2020. INSTITUTO TRATA BRASIL. Ranking do saneamento. São Paulo, 2018. Disponível em: https://bityli.com/nPISI. Acesso em 12 dez. 2020.

IPEA. Atlas da Violência. Brasília: IPEA, 2020. Disponível em: https://bityli.com/NaO9i. Acesso em 19 dez. 2020.

LAPORT, B. São João de Meriti e sua questão demográfica. Revista Pilares da História, Duque de Caxias, v. 12, p. 27-33, 2013. MARX, K; ENGELS, F. A Ideologia Alemã. São Paulo: Moraes, 1987. MÉSZÁROS, I. A teoria da alienação. Rio de Janeiro: Zahar Editores, 1981.

MONTEIRO, W. T. Fios de uma história: entrelaces em experiências de educação de jovens e adultos em Duque de Caxias (anos 1980/1990). 2007. 125f. Dissertação (Mestrado em Educação) Universidade Estadual do Rio de Janeiro, Rio de Janeiro, 2007.

ROCHA, A. S. Baixada Fluminense: representações entre o desenvolvimento, a violência e o descaso. In: ROCHA, A. S. (org). Baixada Fluminense: estudos contemporâneos e (re)descobertas histórico-geográficas. Duque de Caxias: ASAMIH, 2020.

SANTIN, J. R.; FAVRETTO, M. Poder Local, Participação Popular e Clientelismo. Direito, Estado e Sociedade, Rio de Janeiro: PUC, n. 50 p. 126-148, jan./jun. 2017.

SANTOS, S. C. C. D. Lutas do movimento negro por educação: saberes em fronteira no currículo da EDUCAFRO. 2019. 172f. Dissertação (Mestrado em Educação) - Universidade Estadual do Rio de Janeiro, Rio de Janeiro, 2019.

SAVIANI, D. Pedagogia histórico-crítica: primeiras aproximações. 9. ed. São Paulo: Autores Associados, 2005. 
TCE-RJ. Estudos Socioeconômicos municípios do Estado do Rio de Janeiro: São João de Meriti 2019. Rio de Janeiro, 2019. Disponível em: https://bityli.com/UvQDk. Acesso em 19 dez. 2020. THOMPSON. E. P. A Formação da Classe Operária Inglesa. A árvore da liberdade. Rio de Janeiro: Paz e Terra, 1987.

Submetido em: Julho/ 2021.

Aceito em: Agosto/ 2021. 